\title{
Fifth-year medical students' perspectives on rural training in Botswana: A qualitative approach
}

P Kebaabetswe, ${ }^{1} \mathrm{PhD}$, MPH; T Arscott-Mills, ${ }^{2,3,4} \mathrm{MD}$, MPH; K Sebina, ${ }^{1} \mathrm{BSc} ;$ M B Kebaetse,,${ }^{1,5} \mathrm{PhD}$; O Makgabana-Dintwa, ${ }^{1} \mathrm{MPH} ; \mathrm{L}$ Mokgatlhe, ${ }^{6} \mathrm{PhD}$; G Tawana, ${ }^{1}$ BSc; D O Mbuka, ${ }^{7}$ MD, MMed Fam Med; O Nkomazana, ${ }^{1,8}$ MB ChB, FCOphth, MSc CEH

${ }^{1}$ Medical Education Partnership Initiative (MEPI), Faculty of Medicine, University of Botswana, Gaborone, Botswana

${ }^{2}$ Botswana-University of Pennsylvania (Botswana-UPenn) Partnership, Gaborone, Botswana

${ }^{3}$ Department of Pediatrics, Perelman School of Medicine, University of Pennsylvania, PA, USA

${ }^{4}$ Department of Paediatrics, Faculty of Medicine, University of Botswana, Gaborone, Botswana

${ }^{5}$ Department of Medical Education, Faculty of Medicine, University of Botswana, Gaborone, Botswana

${ }^{6}$ Department of Statistics, Faculty of Social Sciences, University of Botswana, Gaborone, Botswana

${ }^{7}$ Department of Family Medicine, Faculty of Medicine, University of Botswana, Gaborone, Botswana

${ }^{8}$ Department of Surgery, Faculty of Medicine, University of Botswana, Gaborone, Botswana

Corresponding author: T Arscott-Mills (tonyaarscottmillsbup@gmail.com)

Background. The curriculum of the Faculty of Medicine at the University of Botswana includes rural community exposure for students throughout their 5 years of training. In addition to community exposure during the first 2 years, students complete 16 weeks of family medicine and 8 weeks of public health medicine. However, as a new faculty, students' experiences and perceptions regarding rural clinical training are not yet known.

Objective. To describe the experiences and perceptions of the 5th-year medical students during their rural training and solicit their recommendations for improvement.

Methods. This qualitative study used face-to-face interviews with 5th-year undergraduate medical students $(N=36)$ at the end of their family medicine rotation in Mahalapye and Maun villages. We used a phenomenological paradigm to underpin the study. Voice-recorded interviews were transcribed and analysed using Atlas TI version 7 software (USA).

Results. Three main themes were identified: (i) experiences and perceptions of the rural training environment; (ii) perceptions of the staff at rural sites; and (iii) perceptions of clinical benefits and relevance during rural training. While the majority of students perceived rural training as beneficial and valuable, a few felt that learning was compromised by limited resources and processes, such as medical equipment, internet connectivity and inadequate supervision.

Conclusion. While the majority of students perceived rural training as beneficial, students identified limitations in both resources and supervision that need to be improved. Understanding students' rural training experiences and perceptions can help the Faculty of Medicine, stakeholders and site facilitators to guide future rural training implementation.

Afr J Health Professions Educ 2017;9(3):144-147. DOI:10.7196/AJHPE.2017.v9i3.738

Many medical schools currently offer medical students the opportunity to spend time in rural settings as part of their education. The expectation is that such experience will encourage future interest in rural practice. This approach is supported by studies showing that rural experiences during training can increase the likelihood of students choosing to practise in rural areas after graduation. ${ }^{[1-3]}$

The first medical school in Botswana opened at the University of Botswana in 2009 and the first cohort of students graduated in 2014. The school trains doctors in Gaborone, an urban setting, with rural clinical placements in Serowe, Molepolole, Mahalapye and Maun. The teaching curriculum emphasises that the training should take place at all levels of the health system; therefore, the curriculum includes rural training to enhance students' learning and experiences.

The curriculum includes exposure to rural healthcare in various formats throughout the 5-year programme. The places where students do rural training are highlighted in Fig. 1. During each of the 1st and 2nd years students complete 4 weeks' training in a public health community, in each of the 3rd and 5th years they complete 8 weeks of family medicine, and in the 4th year they complete 8 weeks of public health. This gives a total of 32 weeks of rural exposure throughout the 5 years. As an example, the curriculum for the family medicine rotation involves problem-based learning sessions, ward rounds and outpatient care, as well as attendance at continuing medical education lectures. Tutorials and practicals focus on patient-centred consultations, the doctor, the patient and environmental factors in consultation, communication skills (e.g. breaking bad news), motivational interviewing and counselling skills.

Although the medical students in Botswana are exposed to rural training at different levels, their perceptions of the current rural training are unknown. Exploring students' rural experiences and perceptions of the clinical rural training relevance is important to a newly established school. Understanding their experiences and perceptions can help the Faculty of Medicine to improve future rural development and maximise 


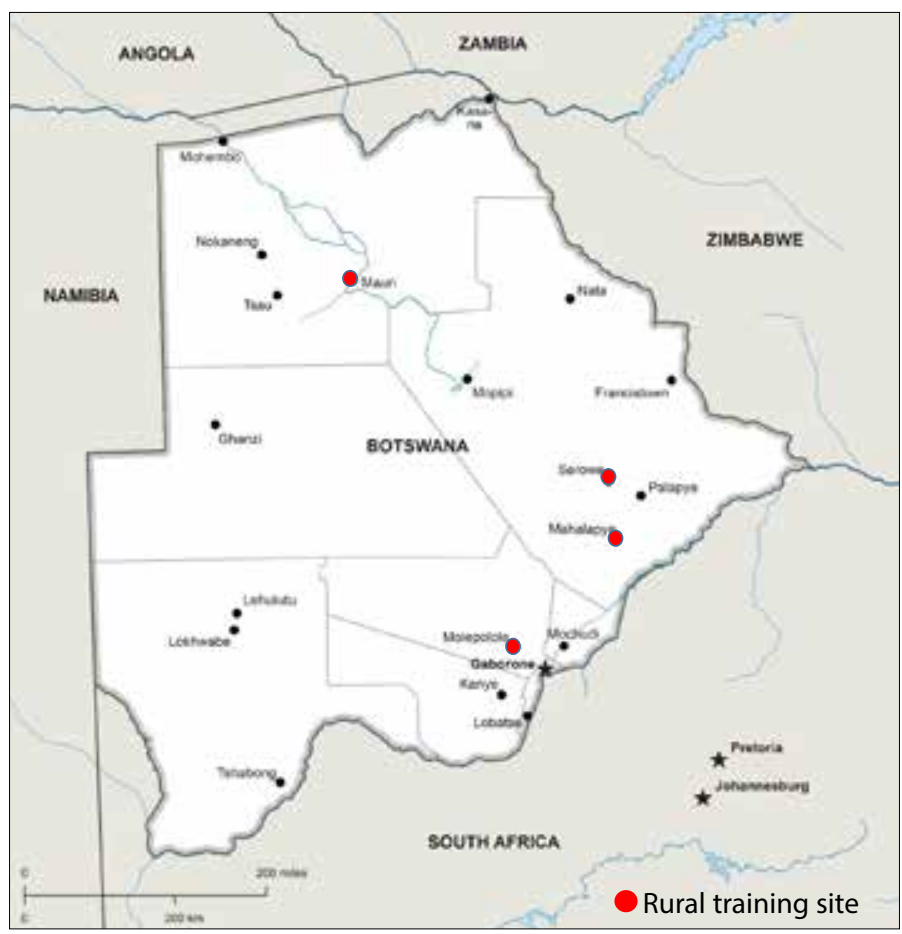

Fig. 1. Map of rural training sites.

students' learning experiences. This article focuses on the experiences and perceptions of 5th-year medical students after completion of the 32 weeks of their rural exposure. The specific objective of the study was to describe the experiences and perceptions of 5th-year medical students during their rural training and solicit their recommendations for improvement.

\section{Methods}

Between October 2013 and June 2014, we conducted an open-ended interview qualitative study among 5th-year medical students after their 8 -week family medicine rotation. Interviews were conducted at the training sites of the Faculty of Medicine, University of Botswana, in Mahalapye, Maun and Gaborone. We used the phenomenological paradigm to underpin the study, as this approach is relevant for formulating the experiences and perceptions of individuals from their own perspectives. ${ }^{[5]}$

\section{Participants' recruitment}

All 36 (16 female, 20 male) 5th-year undergraduate medical students were invited to participate in the study during the last week of their 8-week family medicine rotation. Criteria included having completed the 5th-year rural training rotation at one of the four rural clinical placement sites. Recruitment was done by email; all 5th-year students were informed of the study and were followed up by means of telephone calls inviting them to take part. Of 36 potential 5th-year students recruited, 15 accepted the invitation and 21 declined, citing a busy schedule.

\section{Data collection}

Data were collected from the 15 students who volunteered to take part in the study. After informed consent was obtained, they participated in a face-toface interview at a place and time convenient to them. The interviews were conducted in either Maun or Mahalapye during the last week of the rotation, or in Gaborone after they returned from the rural rotation sites. Although all medical students were fluent in both Setswana and English, they had the right to be interviewed in either of the two languages. Most preferred to mix Setswana and English. The data collection tool included demographic information and a structured open-ended interview guide (Table 1).

Although the questions were not piloted with students, they were reviewed by independent persons, who provided feedback on understanding. Data were collected by three researchers (OMD, GT and KS), with no teaching or clinical interactions with students. Participants were encouraged to openly express their views about rural training. To facilitate data capturing, the interviews were audio recorded after consent had been obtained. The duration of an interview was up to 1.5 hours. Although data saturation was reached after 12 interviews, all 15 interviews with individual participants were included in the analysis. Following data collection, interviews were transcribed and translated by two independent professional transcribers.

\section{Data analysis}

Content data analysis was performed by three researchers (PK, OMD and GT). The team thoroughly read and re-read each transcript, and listened back to the audio-recorded interviews to become familiar with the data and to check all transcripts for errors. The team used the Atlas TI version 7 software (USA) to code and identify common themes and subthemes independently. They discussed their analysis and reached a consensus on the key themes and interpretations.

\section{Ethical considerations}

Ethical approval was obtained from the ethics committees of the University of Botswana (ref. no. UBR/IRB/1454), the Ministry of Health, Botswana (ref. no. PPME 18/8/1 VIII (303), and the University of Pennsylvania, PA, USA (ref. no. 81944). Because of confidentiality, the names of the participants were not written on the interview guide and not used during audio recordings. The tape recordings were locked and kept by the principal investigator. Signed consent was kept locked separately from the data and recordings.

\section{Results}

Three main themes were identified: (i) experiences and perceptions of the rural training environment; (ii) perceptions of the staff at rural sites; and (iii) perceptions of clinical benefits and relevance during rural training.

\section{Experiences and perceptions of the rural training environment}

Students expressed mixed views about the rural training environment. While some claimed that, in general, the rural environment was more relaxed, less hectic and less conducive to learning, others felt that rural areas lacked resources such as simple medical equipment and internet connectivity and were therefore not conducive to learning. Presented below are examples of both positive and negative perceptions.

Table 1. Interview guide

Demographic information

- Please tell me about your rural training experiences. Probe for: rural training environment, the staff and facilities

- In your opinion, was the rural training or exposure during your medical school training beneficial/valuable or not? Please explain your answer

- What challenges, if any, did you encounter during your rural training? How do you think they can be improved? What are your recommendations? 


\section{Positive perceptions}

'I got to see something different from what I was used to seeing at Princes Marina in Gaborone. For the first time I got to work where it wasn't really, really busy, so there was time to focus on one patient at a time and just learn from that and establish a working relationship, so that was good.' (Participant 3)

'I enjoy the rural environment to some degree; enjoy the relaxed nature of most of the places. Also just being in a different environment is something that I have also enjoyed. I tend to have time to even study for other things, yes. It's not very hectic like when I'm in Gaborone.' (Participant 13)

\section{Negative perceptions}

'When you have no equipment, no basic things like an ECG machine and you have a patient who has arrhythmias and you don't have an ECG machine you end up compromising medical. If you need to do a CT on a patient you don't need to send the CTs or the samples anywhere further, you get the results as soon as possible.' (Participant 4)

'I think rural environment kind of delays professional growth because if there are no supplies and no equipment then I won't be able to help as much as I know I could help. But having been placed here for the past seven weeks, I don't think I have learnt as much as I would have learnt when I was in Gabs. I want a place where I can be challenged every day and that will help me grow professionally.' (Participant 10)

\section{Perceptions of the staff and community at rural sites}

Generally, almost all the students felt that people in the rural sites were welcoming and supportive, including those at the hospitals, at the clinics and in the community.

'Generally the people were very welcoming. They respected us more and appreciated us more and they welcomed us more than in the urban setting and even in the hospital people work together and respect each other. Even the community members they respect us, they really appreciate us and welcomed us here and even appreciate us as Batswana doctors. (Participant 1)

'Generally the people were very welcoming. It was, it felt ... warm to be there. The people in the hospitals ... the people just in the town ... yeah, cause I was in Maun. They were very excited, very happy and helpful. I thought that was nice, yes. It would definitely be good to work in that kind of environment, everyone was helpful, even in the hospital.' (Participant 11)

\section{Perceptions of clinical benefits and relevance during rural training}

Students had different views about clinical benefits and the relevance of rural exposure. The majority of students described the rural training as clinically beneficial and valuable, as it offered them the opportunity to apply theoretical knowledge, gain practical skills, learn new cases in a relaxed environment, and appreciate cultural influences on diseases.

Students with negative experiences felt that there were fewer opportunities for learning. They only saw uncomplicated cases because serious ones were referred to city hospitals. Others expressed concerns that there were fewer opportunities for professional growth, as there were few specialists to learn from and shortages of equipment to provide quality care, as well inadequate supervision.

\section{Positive perceptions}

'Rural training is advantageous for me because it widens my scope of learning. I think I learnt much more ... varied content of stuff in a rural setting than ... in a referral hospital where I just focused on surgical cases, but in rural areas there are different things that come on the same day, and its better ... ?' (Participant 8)

'I think rural rotations are beneficial in the sense that you really get to see different things ... you get to see different ... ways that could work and you get to be in a different setting and you get experience. It was a nice experience because I managed to see how culture actually influences diseases so it was nice to see how their culture influences their health around there.' (Participant 13)

'In the rural areas, there are opportunities to practise procedures. So there is not much competition in terms of procedures here. But you go to Marina you compete with third-year medical students, fourth-year and interns that's the problem. I have learnt a lot. Even my experience to actually assist in an operation was in a rural environment which I enjoyed very much.' (Participant 15)

\section{Negative perceptions}

'Having been exposed to a rural area I realised that actually being in an urban area is way better because there you have all the equipment that you need. You know if you need to do a CT on a patient you don't need to send the patient out of the city.' (Participant 4)

'... having been placed here for the past seven weeks, I don't think I have learnt as much as I would have learnt when I was in Gaborone; the quality is low. Actually I think rural areas kind of delayed my professional growth.' (Participant 10)

'There was no teaching during the rural/family medicine rotation; everyone was on their own, unlike in Marina where there are many mentors. I do not think it was beneficial to learning, we just go to hospitals, little learning during morning rounds, then morning meetings, rest of the day you are on your own.' (Participant 1)

\section{Discussion}

Rural training has been found to provide a valuable opportunity to develop skills, competencies and confidence in the management of patients with various conditions. ${ }^{[6-8]}$ The literature also suggests that rural training programmes can have a positive effect on patient care. ${ }^{[9]}$ Additionally, Smith ${ }^{[10]}$ indicates that rural training can have a positive influence and impact on medical students and residents and dispel misconceptions of rural healthcare practices. Consistent with the literature, our findings showed that the majority of students had positive experiences during rural training. They claimed that their learning was enhanced by a relaxed and less hectic rural work environment.

In view of the benefits of rural exposure, students' supervision during rural training is important to maximise positive experiences. The quality of students' supervision during field placements is related to overall student satisfaction. ${ }^{[11,12]}$ In a study to explore undergraduate medical students' satisfaction with faculty support supervision during community placements in Uganda, Mubuuke et al.$^{[13]}$ noted that lack of resources to manage frequent supervision visits to the students while they were in the communities and few available faculty supervisors were key challenges to students. Similarly, our study showed that students experienced inadequate supervision owing to a shortage of clinical staff, which affected learning. As a solution they recommended that rural medical doctors be empowered to supervise undergraduate students during rural training. This model has been supported in the literature. ${ }^{[13]}$

Limited resources can contribute to a dislike of rural exposure. ${ }^{[14]}$ Although rural training is usually done in places with limited resources, 
absence of the internet and web-based support has been found to increase students' perception of academic isolation. ${ }^{[15]}$ Our results showed that limited resources contributed to negative rural experiences. Students recommended that in future rural training sites should be equipped with adequate resources and facilities, such as electricity, water, television and internet.

Although students decried limited resources at rural training sites, interestingly, some felt that the rural areas were not rural enough and they would have preferred exposure to the most remote areas to prepare them for worse experiences in their medical career. When selecting rural training sites it is important to select those that could maximise experiences, while ensuring that the learning environment is optimised.

\section{Conclusion}

The general experiences and perceptions of 5th-year medical students were positive. While the majority perceived rural training as beneficial, students also identified barriers related to both resources and supervision that need to be improved. These results can be used by the university, stakeholders and site facilitators to enhance students' rural experiences and guide future rural training implementation.

\section{Study limitations}

Although issues raised in our study are consistent with findings in other studies, the results are specific to Botswana students. They cannot be generalised to all medical students and it is possible that the students who did not participate would have different views. However, recommendations could be applicable to other similar settings in the region. Although the interviews were conducted by staff not directly involved with the students, it is possible that some students declined to participate because all the interviewers were university staff.

Acknowledgements. The information, content and conclusions presented in the article are those of the authors and should not be construed as the official position or policy of, and endorsements should not be inferred by, the Health Resources and Services Administration (HRSA), US Department of Health and Human Services (HHS), or US government.
Author contributions. PK: planning, design of data analysis, and writing of the manuscript. TAM: planning, design and implementation of the study, and editing of the manuscript. OMD: planning, design and data collection, data analysis, and editing of the manuscript. GT: data collection and editing of the manuscript. KS, MBK, DOM, LM and ON: planning and editing of the manuscript. All authors approved the final version of the manuscript.

Funding. This study was supported by the HRSA, and the US Department of HHS, grant T84HA22125 (Medical Education Partnership Initiative, US\$10 000 000).

Conflicts of interest. None.

1. Tate RB, Aoki FY. Rural practice and the personal and educational characteristics of medical students: Survey of 1279 graduates of the University of Manitoba. Can Fam Phys 2012;58(11):e641-e648

2. Farmer J, Kenny A, McKinstry C, Huysmans RD. A scoping review of the association between rural medical education and rural practice location. Hum Resource Health 2015;6(13):27. https://doi.org/10.1186/s12960-015$0017-3$

3. Holst J, Normann O, Herrmann M. Strengthening training in rural practice in Germany: New approach for undergraduate medical curriculum towards sustaining rural health care. Rural Remote Health 2015;15:3563. 4. Botswana villages. https://www.google.co.bw (accessed 20 October 2016).

5. Davidsen AS. Phenomenological approaches in psychology and health sciences. Qual Res Psychol 2013;10(3):318339. https://doi.org/10.1080/14780887.2011.608466

6. Irlam J, Pienaar L, Reid S. On being agents of change: A qualitative study of elective experiences of medical students at the Faculty of Health Sciences, University of Cape Town, South Africa. Afr J Health Professions Educ 2016;8(1):41-44. https://doi.org/10.7196/AJHPE.2016.v8i1.540

7. Van Schalkwyk SC, Bezuidenhout J, Conradie HH, et al. 'Going rural': Driving change through a rural medical education innovation. Rural Remote Health 2014;14:2493.

8. Kibore MW, Daniels JA, Child MJ, et al. Kenyan medical student and consultant experiences in a pilot decentralised training program at the University of Nairobi. Educ Health (Abingdon) 2014;27(2):170-176 https://doi.org/10.4103/1357-6283.143778

9. Liskowich S, Walker K, Beatty N, Kapusta P, McKays, Ramsden VR. Rural family medicine training site: Proposed framework. Can Fam Phys 2015;61(7):e324-e330.

10. Smith CC. Investigating a rural immersion experience in medical education utilizing narrative inquiry. Narrative Inquiry Bioethics 2012;2(1):55-64. https://doi.org/10.1353/nib.2012.0005

11. Barrett FA, Lipsky MS, Lutfiyya MN. The impact of rural training experiences on medical students: A critical review. Acad Med 2011;86(2):259-263. https://doi.org/10.1097/ACM.0b013e3182046387

12. Roberts C, Daly M, Kumar K, Perkins D, Richards D, Garne D. A longitudinal integrated placement and medical students' intentions to practise rurally. Med Educ 2012;46(2):179-191. https://doi.org/10.1111/j.13652923.2011.04102.x

13. Mubuuke AG, Oria H, Dhabangi A, Kiguli S, Sewankambo NK. An exploration of undergraduate medical students' satisfaction with faculty support supervision during community placements in Uganda. Rural Remote Health 2015;15:3591.

14. Kapanda GE, Muiruri C, Kulanga AT, et al. Enhancing future acceptance of rural placement in Tanzania through peripheral hospital rotations for medical students. BMC Med Educ 2016;16(1):51. https://doi.org/10.1186/ s12909-016-0582

15. Isaac V, Watts 1 , Forster L, Mclachlab CS. The influence of rural clinical school experiences on medical students levels of interest in rural careers. Hum Resource Health 2014;12:48. https://doi.org/10.1186/1478-4491-12-48

Accepted 16 November 2016 